\begin{tabular}{|l|l|l|}
\hline \multicolumn{2}{|c|}{ PublisherInfo } \\
\hline \hline PublisherName & $:$ & BioMed Central \\
\hline \hline PublisherLocation & $:$ & London \\
\hline \hline PublisherImprintName & $:$ & BioMed Central \\
\hline \hline
\end{tabular}

\title{
Mitochondria are transferred
}

\begin{tabular}{|l|l|l||}
\hline \multicolumn{2}{|c|}{ ArticleInfo } \\
\hline \hline ArticleID & $:$ & 4909 \\
\hline \hline ArticleDOI & $:$ & $10.1186 /$ gb-spotlight-20040202-01 \\
\hline \hline ArticleCitationID & $:$ & spotlight-20040202-01 \\
\hline \hline ArticleSequenceNumber & $:$ & 261 \\
\hline \hline ArticleCategory & $:$ & Research news \\
\hline \hline ArticleFirstPage & $:$ & 1 \\
\hline \hline ArticleLastPage & $:$ & 3 \\
\hline \hline & & RegistrationDate : 2004-2-02 \\
\hline ArticleHistory & $:$ & OnlineDate \\
\hline \hline ArticleCopyright & $:$ & BioMed Central Ltd2004-02 \\
\hline \hline ArticleGrants & $:$ & \\
\hline \hline ArticleContext & $:$ & 130594411 \\
\hline \hline
\end{tabular}


Cathy Holding

Email: Cathyholding@aol.com

Despite the importance of the mitochondria in disease, suitable mouse models to study mitochondrial dysfunction have proved difficult to generate because classical genetic techniques cannot be applied to the thousands of individual mitochondria in a single cell. Now, a team of researchers reports the introduction of these organelles from one mouse species into another, generating a mitochondrial mutant model that could be used to elucidate mitochondria-related disease mechanisms.

In the January 26 Proceedings of the National Academy of Sciences, Matthew McKenzie and colleagues at the University of Melbourne demonstrate the successful transfer of species-specific mitochondria into mouse embryos using mitochondrial DNA-depleted embryonic stem cells and cytoplast fusions that results in homoplasmy for the introduced mitochondrial background (Proceedings of the National Academy of Sciences USA 2004, DOI:10.1073/pnas.0303184101).

"The primary focus was being able to demonstrate we have the technologies to modify mitochondrial genetics," said Carl Pinkert, professor of Pathology and Laboratory Medicine at the University of Rochester Medical Center in New York. "We have taken complete mitochondrial genomes from diverse species 2 to 6 million years apart, put these in, and got nuclear/mitochondrial mismatch. The mitochondria won't function properly in concert with the nuclei for energy production."

"Now we can start to understand mitochondrial dynamics - what controls propagation and amplification of specific mitochondrial genomes," Pinkert, who led the group, told The Scientist. "We can start developing models to explain the various mitochondrial disorders."

According to Phil Wood, professor and director of the Department of Genomics at the University of Birmingham, the work marks an important step forward in the attempt to develop mouse models of mitochondrial diseases. "What is needed is a mouse nucleus and human mitochondria bearing specific mitochondrial mutations, that would make a mouse model for human disease. It raises the possibility of following the dynamics of mitochondria in aging using mitochondria marked by different genomes to understand the dynamics of mitochondrial turnover," he told us.

Massimo Zeviani, director of the Unit of Molecular Neurogenetics at the National Institute of Neurology in Milan, agreed."The ultimate aim was to validate the possibility to create transmitochondrial animals," he told The Scientist. "I think they beautifully proved that. The second achievement is to produce a phenotype for clinical and related disorders. This is needed because of the many obstacles to proceeding to understanding."

"One of the major aims is to have some means to test treatment of mitochondrial disease with new drugs," said Zeviani, who was not involved in the study.

However, both scientists expressed concern at the low number of surviving homoplasmic offspring. "Only a few mice survived, and these were only male mice. This raises a lot more questions before models of that sort can be developed," said Wood, who also was not involved in the study. 
"Something else is going on here that is not very clear, something that does not provide for survival of offspring for those you feel should have been there, especially females. It is a little unclear whether it is an environmental thing," he said.

The mitochondrial line is effectively extinguished in these offspring, as males cannot transmit the mitochondrial phenotype. "Although they have proved foreign mitochondrial DNA can be transmitted, they don't yet have a stable lineage. However, they have proved they can generate xenomitochondrial mice showing one germ line passage, at least," Zeviani said.

The homoplasmic mice have normal physiology and development, but have subtle defects in oxidative phosphorylation. "But no further biochemical information is reported. I am surprised by this. We do not know if we are dealing with a useful phenotype yet," he said.

However, both Wood and Zeviani both feel that this is a significant step forward. "I think this is a pretty novel outcome," Wood said. "They have developed a new technique to pursue a model, and it is a very important contribution."

\section{References}

1. Mitochondrial function: the heart of myocardial preservation

2. Medicinal and genetic approaches to the treatment of mitochondrial disease

3. Proceedings of the National Academy of Sciences USA, [http://www.pnas.org/]

4. University of Melbourne, [http://www.unimelb.edu.au/] 